\title{
Retraction Note to: formation of polyelectrolyte multilayer films with controlled wettability via layer-by-layer electric-assembly
}

\author{
Meng-Yuan Zhang ${ }^{1} \cdot$ Qing Shen ${ }^{1}$ \\ Published online: 23 June 2020 \\ (C) Springer-Verlag GmbH Germany, part of Springer Nature 2020
}

Retraction Note to: Colloid and Polymer Science (2019) 297:883-889.

https://doi.org/10.1007/s00396-019-04513-6

The editors have retracted this article [1] because after publication concerns were raised regarding the validity of the conclusions drawn. Post-publication peer review has revealed that the experimental procedure is not described adequately, that the assignment of the signals in the Fourier-Transform infrared spectra are partially wrong, and that the mechanism proposed for the effect of the applied voltages on the surface tension is not justified by the data. The main claim of the paper cannot be reliably reached. All authors do not agree to this retraction.

[1] Zhang, M., Shen, Q. Formation of polyelectrolyte multilayer films with controlled wettability via layer-by-layer electric-assembly. Colloid Polym Sci 297, 883-889 (2019). https://doi.org/10.1007/s00396-019-04513-6

Publisher's note Springer Nature remains neutral with regard to jurisdictional claims in published maps and institutional affiliations.

The online version of the original article can be found at https://doi.org/ 10.1007/s00396-019-04513-6

Qing Shen

sqing@dhu.edu.cn

1 State Key Laboratory for Modification of Chemical Fiber and Polymer Materials, Polymer Department of Donghua University, 2999 N. Renmin Rd., Songjiang Shanghai 201620, People's Republic of China 